\title{
Aggregate Economic Shocks, Child Schooling, and Child Health
}

Francisco H. G. Ferreira and Norbert Schady

Do aggregate income shocks, such as those caused by macroeconomic crises or droughts, reduce child human capital? The answer to this question has important implications for public policy. If shocks reduce investments in children, they may have a long-lasting impact on poverty and its intergenerational transmission. The authors develop a simple framework to analyze the effects of aggregate economic shocks on child schooling and health. They show that the expected effects are theoretically ambiguous because of a tension between income and substitution effects. They then review the recent empirical literature on the subject. In richer countries, like the United States, child health and education outcomes are counter-cyclical: they improve during recessions. In poorer countries, mostly in Africa and low-income Asia, the outcomes are procyclical: infant mortality rises and school enrollment and nutrition fall during recessions. In the middle-income countries of Latin America, the picture is more nuanced: health outcomes are generally procyclical and education outcomes counter-cyclical. Each of these findings is consistent with the simple conceptual framework. The authors discuss possible implications for expenditure allocation. JEL codes: I30, J13, 015

Investments in children's health and education have long-term consequences. In both the United States and the United Kingdom, low levels of cognitive development in childhood, measured by a child's performance in tests administered as early as 22 months of age, have been shown to be important predictors of adult wages (Currie and Thomas 1999; Case and Paxson 2008). In developing countries, long-term panels suggest that adverse experiences in early childhood result in worse outcomes in adulthood. A well-known study in Jamaica shows that children who were stunted (had height-for-age two standard deviations or more below that of a reference population) in early childhood were significantly more likely to have deficits in cognition and school achievement in adolescence

(C) The Author 2009. Published by Oxford University Press on behalf of the International Bank for Reconstruction and Development / THE WORLD BANK. All rights reserved. For permissions, please e-mail: journals.permissions@oxfordjournals.org doi;10.1093/wbro/lkp006 Advance Access publication July 8, 2009 
and to have poorer emotional and behavioral outcomes (Walker and others 2005, 2007). In Guatemala, children exposed to a nutritional intervention have better reading comprehension and perform better on tests of cognitive development in adulthood, and they earn higher wages (Hoddinott and others 2008; Maluccio and others 2008; see also Martorell 1999). Almost universally, dropping out of school earlier is associated with lower labor earnings in adulthood.

The persistence of the effects of early life investments in nutrition, health, and education has rightly attracted considerable academic and policy interest in their determinants. In this paper, we review the recent empirical evidence on one particular set of factors that affect investments in the human capital of children, namely aggregate economic shocks. Following the literature, we focus primarily on the effects of the macroeconomic cycle, understood as the sequence of aggregate economic expansions (booms) and contractions (recessions or crises). In some cases, the shocks were caused by policy errors or by exogenous variations in the price of a key export product. In other settings, the contraction resulted from natural phenomena, such as droughts. The common feature of the macroeconomic events we review was a substantial temporary reduction in overall production and income levels. ${ }^{1}$

There is now a large literature on the effects of such aggregate shocks on both schooling and health outcomes for children in countries that span the development spectrum: from Zimbabwe to the United States. Although early work on this topic often betrayed a general presumption that economic crises would have a negative impact on education and health outcomes, the actual empirical findings reveal no such simple regularity. ${ }^{2}$ Some recessions have led to reductions in school enrollment, as in Costa Rica between 1981 and 1982, while others have led to substantial increases, as in the United States during the Great Depression. There is similar variation for child health outcomes: negative covariate shocks in Zimbabwe, associated with the 1982-84 drought, led to persistent losses in height-for-age for affected children, while infant and adult mortality are both procyclical in the United States.

We review the literature on the effects of aggregate shocks on child education and health in light of a simple conceptual framework which relates the disparate nature of these outcomes to the basic economic mechanisms at work. We organize our review of the evidence in terms of the predictions of our framework, and we find that it is helpful in understanding the diversity of experience across countries and periods. In concluding, we consider implications for the policy debate.

\section{A Conceptual Framework}

In this section, we outline a simple conceptual framework for understanding the likely impact of aggregate economic shocks on education and health outcomes. 
The basic insight is that aggregate (as opposed to idiosyncratic) shocks have both income and substitution effects on households. The income effect arises from changes in the resources available to the household for investment in health-promoting goods and consumption. The substitution effect arises from changes in wage rates (for children and adults), which affect the opportunity cost of time spent in school (for children) or in health-promoting activities (for adults).

When there is a recession, the income effect works toward a deterioration of outcomes-less child schooling, higher infant mortality — especially if households are credit constrained. The substitution effect works in the opposite direction and results in improved education and health status. Which of these two effects dominates is an empirical matter and will vary from country to country and by the nature of the crisis. In addition, reductions in public expenditures on education and health can amplify any negative effects of a shock on households. A more detailed description of the framework, including diagrammatic illustrations, can be found in the working-paper version of this article (Ferreira and Schady 2008).

\section{Schooling Outcomes}

Consider a simple model of educational choice, with unitary households, in which agents live for two periods and derive utility from private consumption in each period. Schooling is an investment, useful only as a means for increasing earnings in the future-it does not generate utility directly. In the first period, agents must decide how to divide their time between schooling and work (child labor). If they work, they are paid an unskilled wage. The wage they are paid in the second period depends on how much human capital they chose to acquire in period $1 .^{3}$

The key trade-off, therefore, is between child work-that increases first-period consumption-and schooling-that increases second-period consumption. The optimal schooling choice then depends on the following four factors: the child wage rate in period 1; other sources of income for the household; the expected returns to schooling in period 2; and the quality of the schools. It also depends on whether or not the family has access to a functioning credit market which would allow it to separate the investment and consumption decisions.

When a recession hits the economy, the shock negatively affects at least two parameters in this decision problem: the child wage rate and other sources of household income that determine period 1 consumption.

The effect on schooling depends, first of all, on whether the household has access to a functioning credit market. If it does, the household borrows to smooth out the income shock. There is therefore no income effect of the recession on schooling. But there is a substitution effect: the child wage rate is now lower, reducing the opportunity cost of studying. The implication is that, with 
functioning credit markets and when schooling is seen as an investment rather than a consumption good, we should expect schooling to behave countercyclically: enrollment should rise in recessions and fall during expansions.

There are, however, three caveats to this prediction. First, if the recession were somehow to lower expected future returns to schooling, this would shift the demand curve downwards, leading to an offsetting effect on the quantity demanded. This would be the case, for instance, if a recession led to larger (proportional) declines in income for more skilled workers, and if a component of this shift were expected to be permanent. Second, if the recession reduced the contemporaneous quality of schooling, say through reduced public expenditures on materials or teacher salaries, we would also expect it to reduce demand for education. Third, if schooling is seen in part as a consumption good, not just an investment, then there would be an income effect arising from the impact of the recession on the full intertemporal budget constraint (as opposed to the effect on contemporaneous income).

In most developing countries, however, access to credit markets is by no means universal. If credit markets are missing, or function very badly, then first-period consumption is a shifter of the demand for schooling. As first-period consumption falls, so does the optimal schooling choice at every wage rate, because the marginal utility of period 1 consumption rises relative to that of period 2 consumption (which is what schooling buys). There are now two effects from the recession: an income effect and a substitution effect. The substitution effect pushes households along the demand curve for schooling (toward more schooling, as a result of the falling child wage), while the income effect shifts the entire demand curve inwards (toward less schooling, at any given child wage). When credit markets are missing or imperfect, the effect of a recession on the quantity of schooling demanded is therefore theoretically ambiguous.

\section{Health and Nutrition Outcomes}

The analogy between health outcomes and education outcomes, which are often discussed alongside one another, is not perfect. Nevertheless, there are important similarities. Child health can also be seen as an investment, which depends on inputs in period 1 and which generates higher earnings in period 2. In this case, inputs into the "production" of health status of children include the consumption of health-promoting goods. At their most basic, these consist of nutritious foodstuffs, but may also include protective clothing and apparel, such as shoes or mosquito nets, medicines, and hygiene products. It also depends on time-intensive activities conducted by parents, especially mothers. These include antenatal check-ups for pregnant women or preventive health care visits for children, breastfeeding, cooking healthy meals, or collecting clean water. 
As with schooling, if households are not credit constrained, a recession will not have an income effect on child health. However, there is a substitution effect: during a recession, adult wages fall, and the opportunity cost of carrying out time-intensive activities decreases. More generally, if households are credit constrained, their ability to smooth out the income shock is limited, and there will be an income effect which results in a reduction in the consumption of healthpromoting goods. As with schooling, this income effect will also be apparent if child health is seen, at least in part, as a consumption good rather than as an investment.

In the case of child health status, there are two additional effects of a recession that need to be considered. First, health-reducing goods such as smoking and drinking may also be normal, in which case consumption of them would decrease during recessions. Second, there may be changes in the composition of women giving birth. This is because decreases in women's wages, caused by an aggregate shock, also have income and substitution effects on fertility. The income effect would imply a reduction in the number of children that are desired. However, children are time intensive, so the substitution effect would result in women having more children during a crisis. The relative magnitude of the income and substitution effects on fertility is likely to vary across women and may be correlated with the characteristics that help determine child health. For example, higher-risk women may be more (less) likely to postpone birth during a recession and this, in turn, could lead to better (worse) health outcomes for young children during a crisis. This, too, is an empirical matter, and one which has been considered carefully in a handful of the papers we discuss below.

\section{Predictions of Conceptual Framework}

In addition to drawing attention to the theoretical ambiguity of the effect of aggregate shocks, our simple conceptual framework provides some testable predictions of which factors are likely to determine the net effects of aggregate economic shocks on child schooling and health outcomes. We highlight four such factors.

First, the degree of development of credit markets matters. In particular, we should expect smaller income effects in countries where access to consumer credit is more widespread and is better able to reach middle-income and poor households than in those where credit markets are undeveloped or inaccessible.

Second, if access to credit is limited, the initial level of income matters, and this may result in differences in the effects of a downturn across countries and across individuals within a given country. This is the case for both schooling and health, albeit for somewhat different reasons. In the case of health, the marginal impact of a dollar of consumption on child health will be higher in a very poor country (or for very poor people in any country), where it is used to buy more nutritious 
food, than in richer countries (or for richer households), where it is used on less essential commodities. As a result, a given proportional reduction in income may lead to a larger deterioration in health status in poorer countries (or among poorer households).

In the case of schooling, the income effect of a downturn will in general also be larger in poorer countries or among poorer households. This is because when income (or consumption) is higher, the marginal utility of consumption is lower. As a result, households will be more willing to accept a given proportional income loss when their initial (prerecession) income levels are higher than when they are very low, perhaps at or not much above a "subsistence" level. It follows that poorer households will in general be more likely to take their children out of school and put them in the labor market during a recession than their better-off counterparts. $^{4}$

In sum, we would expect that the same proportional reduction in income levels will have a larger negative impact on schooling and health in poorer countries. This would lead us to expect that rich countries, like the United States, would be more likely to have counter-cyclical health and schooling outcomes (that is, outcomes that improve during recessions) than poor countries, like those in SubSaharan Africa, where we would expect outcomes to be procyclical (that is, health and education status worsen during recessions). The impact of a recession on middle-income countries, such as those in much of Latin America or Eastern Europe, is less clear; it may also be different for health and education outcomes, as we discuss below.

Third, for a given initial level of income, the magnitude and expected duration of the crisis matter. Deeper and longer crises are more likely to lead to procyclical outcomes in schooling and health.

Fourth, controlling for other characteristics of the recession, any reductions in the quality of the available public education or health services reinforce the income effect. The precise mechanism through which this "quality effect" operates depends on the relative importance of the private and public sectors in the provision of these services. For households using the private sector, the quality effect is simply an aspect of the income effect: households can afford less and can adjust their demand either on the quantity or quality margin (or both) say by visiting cheaper providers or cutting down on some medicines. Where the public sector is an important provider, however, there may really be a "quality effect" that is additional to the income effect for the individual household: if public spending on health or education is procyclical (as is often the case in developing countries), and if there is some link between expenditures and service quality, then cuts in public spending on these services may reduce the value to households of using schooling or health services. ${ }^{5}$ 
This would lead us to expect that recessions where public expenditures on education and health are more protected would be more likely to show a countercyclical pattern in education and health.

\section{Empirical Evidence}

In this section, we review the evidence on aggregate shocks and child humancapital outcomes in light of the conceptual framework discussed above and find that theory and evidence are quite consistent. We first focus on schooling and then on child health and nutrition.

\section{Child Schooling}

There are a number of papers that consider the impact of aggregate economic shocks on schooling outcomes in the developing world. Many of these focus on Latin America, including Binder (1999) and McKenzie (2003) on macroeconomic crises in Mexico; Schady (2004) on the economic crisis of the late 1980s in Peru; Duryea and Arends-Kuenning (2003) on economic fluctuations in Brazil; Funkhouser (1999) on a recession in Costa Rica in 1981-83; and Maluccio (2005) and Kruger (2007) on the effects of changes in coffee prices on schooling outcomes in coffee-growing areas in Nicaragua and Brazil, respectively. Outside Latin America, Thomas and others (2004) consider the impact of the 1998 crisis in Indonesia; Jensen (2000) analyzes the effect of the 1986-87 drought in Côte d'Ivoire; and World Bank (2007) focuses on the impact of deviations from longterm rainfall in Malawi.

Before reviewing the evidence from developing countries, it is instructive to briefly discuss studies that focus on the United States. A number of papers consider high-school enrollment and graduation rates during the Great Depression. Goldin (1999) shows that the biggest increase in high-school enrollment and graduation rates in the United States took place between 1928 and 1938 (see also Black and Sokoloff 2006). Further, as Goldin points out, "between 1928 and 1938, Delaware, New Jersey, New York, and Pennsylvania, all hard hit by the unemployment of the Great Depression, experienced increases in their graduation rates that were among the greatest (of any state) on a percentage point basis" ( $\mathrm{p}$. S79). This counter-cyclical pattern in investments in education appears more recently, too: various authors have shown that college enrollment rates in the United States increase during economic downturns and fall when the economy picks up. For example, Betts and McFarland (1995) show that a 1 percent increase in the unemployment rate of all adults is associated with a 4 percent increase in full-time attendance at community colleges, while Kane (1994) shows 
that the enrollment of both blacks and whites in college is negatively associated with average weekly earnings in manufacturing.

Turning to Latin America, Binder (1999) analyzes the relationship between changes in per capita GDP and school retention rates (school enrollment at the close of the school year, divided by school enrollment at the beginning of the year), and continuation rates (the number of students beginning a given school level divided by those who graduated in the previous school year from the earlier school level) in Mexico. Over the period she analyzes, 1977-94, Mexico saw two sharp macroeconomic contractions: in 1982-83, when per capita GDP fell by 9 percent, and in 1986, when per capita GDP fell by 6 percent. Binder shows that school retention and continuation rates in Mexico over the period were generally counter-cyclical, with sharp positive spikes in outcomes corresponding to the periods when the economy was contracting. ${ }^{6}$

McKenzie (2003) studies the effect of the Mexican Peso crisis of 1995-96 on a variety of outcomes, including school enrollment rates. The Peso crisis was a sharp setback to aggregate living standards: GDP per capita fell by 8 percent and real wages contracted by 21.7 percent. McKenzie uses the Encuesta Nacional de Ingresos y Gastos de los Hogares household surveys for 1992, 1994, 1996, and 1998 to estimate the effects of the crisis on schooling. ${ }^{7}$ He uses a differences-indifferences approach to test for changes in school enrollment leading up to and after the crisis. He shows that school enrollment grew by more between 1994 and 1996 (the crisis period) than either between 1992 and 1994 (before the crisis) or between 1996 and 1998 (after the crisis). Put differently, after accounting for underlying trends, enrollment rates were significantly higher in the crisis year, 1996, than they were in either the precrisis or postcrisis years. Table 1 , reproduced from his paper, shows that the increase in the growth rate of enrollment between 1994 and 1996 (relative to changes over the 1992-94 period) is particularly apparent among boys aged 15-20. The same group also saw significant declines in enrollment between 1996 and 1998 (relative to changes over the 1994-96 period). Similar, if somewhat less clear, patterns are also apparent for girls in this age group.

The economic crisis in Peru in the late 1980s was particularly deep. As a result of macroeconomic mismanagement in 1985-87, GDP per capita fell by 10.5 percent in $1988,13.4$ percent in 1989 , and 6.9 percent in 1990 , for a cumulative drop of approximately 30 percent. ${ }^{8}$ Inflation skyrocketed during the crisis, reaching almost 7,500 percent in 1990. Wages and household consumption collapsed. While there are no comparable data for the country as a whole, per capita consumption in Lima, as measured by household surveys, fell by approximately 50 percent between 1985 and 1990 (Glewwe and Hall 1994). The collapse in real wages was even more dramatic - estimates for Lima suggest that 
Table 1. The Impact of the 1995 Mexican Peso Crisis on School Attendance

\begin{tabular}{|c|c|c|c|c|c|c|}
\hline \multirow{2}{*}{ Age } & \multicolumn{4}{|c|}{ Boys } & \multicolumn{2}{|c|}{ Difference-in-difference p-value } \\
\hline & 1992 & 1994 & 1996 & 1998 & $($ T96-T94)-(T94-T92) & $($ T98-T96) $-($ T96-T94) \\
\hline $5-6$ & 0.73 & 0.80 & 0.86 & 0.85 & 0.817 & $0.006^{*}$ \\
\hline $7-8$ & 0.94 & 0.96 & 0.97 & 0.97 & 0.154 & 0.502 \\
\hline $9-10$ & 0.97 & 0.96 & 0.97 & 0.98 & 0.412 & 0.963 \\
\hline $11-12$ & 0.92 & 0.94 & 0.94 & 0.96 & 0.151 & 0.319 \\
\hline $13-14$ & 0.79 & 0.79 & 0.82 & 0.83 & 0.238 & 0.507 \\
\hline $15-16$ & 0.52 & 0.52 & 0.58 & 0.58 & $0.064^{* *}$ & $0.048^{* * *}$ \\
\hline $17-18$ & 0.33 & 0.31 & 0.36 & 0.35 & $0.012^{* * *}$ & $0.038^{* * *}$ \\
\hline $19-20$ & 0.22 & 0.22 & 0.28 & 0.25 & $0.039^{* * *}$ & $0.010^{* * *}$ \\
\hline $21-22$ & 0.18 & 0.19 & 0.19 & 0.19 & 0.849 & 0.661 \\
\hline $23-24$ & 0.13 & 0.11 & 0.10 & 0.11 & 0.589 & 0.317 \\
\hline $25-26$ & 0.05 & 0.07 & 0.07 & 0.06 & 0.246 & 0.614 \\
\hline \multicolumn{7}{|c|}{ Girls } \\
\hline $5-6$ & 0.72 & 0.82 & 0.87 & 0.84 & $0.061^{* *}$ & $0.001^{*}$ \\
\hline $7-8$ & 0.95 & 0.96 & 0.98 & 0.97 & 0.912 & $0.026^{* * *}$ \\
\hline $9-10$ & 0.96 & 0.97 & 0.97 & 0.97 & 0.178 & 0.734 \\
\hline $11-12$ & 0.90 & 0.91 & 0.92 & 0.93 & 0.483 & 0.493 \\
\hline $13-14$ & 0.72 & 0.73 & 0.76 & 0.78 & 0.640 & 0.829 \\
\hline $15-16$ & 0.48 & 0.49 & 0.54 & 0.51 & 0.452 & $0.033^{* * *}$ \\
\hline $17-18$ & 0.33 & 0.31 & 0.34 & 0.32 & $0.041^{* * *}$ & $0.046^{* * *}$ \\
\hline $19-20$ & 0.19 & 0.21 & 0.23 & 0.20 & 0.915 & 0.113 \\
\hline $21-22$ & 0.14 & 0.15 & 0.16 & 0.15 & 0.992 & 0.570 \\
\hline $23-24$ & 0.07 & 0.09 & 0.09 & 0.08 & 0.202 & 0.789 \\
\hline $25-26$ & 0.03 & 0.06 & 0.05 & 0.05 & $0.031^{* * *}$ & 0.842 \\
\hline
\end{tabular}

Note: * significant at the 1 percent level; ${ }^{* *}$ Significant at the 10 percent level; ${ }^{* *}$ significant at the 5 percent level.

The difference-in-difference $p$-values correspond to tests of equality of the growth in school attendance between $(T 2-T 1)-(T 1-T 0)$ for different years.

Source: McKenzie (2003).

real wages fell by 80 percent between 1987 and 1990 (Saavedra 1998; Saavedra and Maruyama 1998).

Schady (2004) uses comparable, nationally representative living standard measurement study (LSMS) household surveys for $1985 / 86,1991$, and $1997^{9}$ to analyze the impact of this recession on schooling outcomes. Schady first shows that the probability of being enrolled in school was similar before, during, and after the crisis - if anything, enrollment rates in 1997 were lower than during the crisis year of 1991; the magnitude of the difference is small, approximately 1-2 percentage points, although it is statistically significant. More striking is the difference in the probability that children work, which is much lower during the crisis 
Table 2. The Impact of the Peruvian Crisis of 1988-92 on the Number of Years of School Attained

\begin{tabular}{lcc}
\hline & No controls & Including controls \\
\hline Years of crisis exposure & $0.050^{*}$ & $0.043^{*}$ \\
Crisis exposure $=1$ & 0.008 & 0.035 \\
Crisis exposure $=2$ & -0.011 & 0.089 \\
Crisis exposure $=3$ & $0.204^{*}$ & $0.173^{* *}$ \\
Crisis exposure $=4$ & $0.184^{*}$ & $0.234^{*}$ \\
Crisis exposure $=5$ & $0.224^{*}$ & $0.199^{* *}$ \\
\hline
\end{tabular}

Note: * significant at the 5 percent level; ** Significant at the 10 percent level.

The upper panel reports results from regressions in which the number of years of crisis exposures enters linearly. The lower panel includes five dummies corresponding to the number of years of crisis exposure, with the omitted category being children who were not school-aged during the crisis years, 1988-92. Controls include variables for child gender, parental education, household size, the number of children in a household in six age categories, and municipality fixed effects. The sample for the specifications with controls is limited to municipalities that were visited in the 1985/86, 1991, and 1997 rounds of the LSMS.

Source: Schady (2004).

than before or after. For older school-aged children, ages $12-17$, this probability is between 16 and 22 percentage points lower in 1991 than in 1985/86 or 1997.

Schady (2004) also analyzes the impact of the crisis on the number of years of schooling attained. Table 2, reproduced from his paper, shows that children who were school-aged during the entire crisis period have completed, on average, about 0.25 more years of schooling at any given age than those who were not school-aged during the crisis (upper panel). Schooling is completed in whole years, rather than fractions, so a more intuitive description of this result is that every fourth child who was fully exposed to the crisis had completed one more year of schooling than a comparable child who was not exposed. A disaggregation of these results to account for differences by the number of years of exposure to the crisis suggests that the positive effects of the crisis on school attainment levels are only apparent for children with "high" levels of exposure- that is, children who were school-aged for at least three of the five crisis years (lower panel). Schady suggests that the increase in school attainment during the recession may have partly been a result of the decrease in child labor, which freed up time that children could expend in more "effort" at school.

Duryea and Arends-Kuenning (2003) study the effects of macroeconomic crises on schooling outcomes in urban Brazil. The period covered by their analysis includes two aggregate economic contractions: between 1981 and 1983 (when GDP per capita fell by 13 percent, following adoption by the government of an 
austerity plan agreed upon with the International Monetary Fund) and between 1990 and 1992 (when GDP per capita fell by 8 percent, following a freeze in access to bank accounts intended to reduce inflation). Duryea and ArendsKuenning first show that there is no evidence in the aggregate data that school enrollment rates changed appreciably for either boys or girls. They then exploit the variation across states in the timing and depth of the economic shocks. Specifically, they construct state-level measures of aggregate labor market conditions by calculating the mean wage of low-skilled men, which they define as the average wage of men with less than four years of schooling living in a given state. They show that an increase in unskilled wages is associated with a higher probability that a child is employed and with a lower probability that he or she is in school. This effect is somewhat more muted during crisis years, but the sign of the regression coefficient is the same-in crisis and noncrisis years, higher statelevel wages for low-skilled workers are associated with a lower probability that a child will attend school. More recently, López Bóo (2008) also finds evidence of counter-cyclical schooling behavior during the 1998-2002 financial crisis in Argentina.

Funkhouser (1999) studies the effects of a sharp decline in living standards in Costa Rica, between 1981 and 1983. This recession, which followed the adoption of a fiscal austerity package, resulted in a contraction of GDP of 14 percent between 1981 and 1982, and a fall in real wages of approximately 50 percent between 1981 and 1983. Funkhouser shows that, unlike the pattern found in Mexico, Brazil, and Peru, there was a drop in school enrollment rates of approximately 6 percent between 1981 and 1982, with larger changes in rural areas, and an increase in the fraction of children working during the same period. However, when he compares the educational attainment of children who were exposed to the crisis and those who were not, at ages 18, 19, 20-22, and 2325 , there are no differences in attainment between the two groups. It thus appears that the drop in school enrollment rates was only temporary, and children who were exposed to the crisis made up schooling deficits later on. ${ }^{10}$

In Nicaragua, Maluccio (2005) investigates the effects of a sudden reduction in the price of coffee between 2000 and 2002. The data he uses were collected for an analysis of the impact of the Nicaraguan Pilot conditional cash transfer (CCT) program, known as the Red de Protección Social. These data are not nationally representative-rather, they cover households in select rural areas. Maluccio first uses household survey data to show that, between 2000 and 2002, per capita consumption for households in the control group-those that were randomly assigned not to receive transfers from the Red-fell by an average of 10 percent. The reduction in consumption in coffee-growing areas was larger, approximately 27 percent. Concurrent with these reductions in consumption levels, school enrollment of children aged 7-12 increased, and increased particularly in 
coffee-growing areas. For example, among boys, school enrollment increased by 15 percentage points, which suggests that the opportunity cost of going to school fell sharply.

Kruger (2007) studies the effects of changes in the county-level value of coffee production in coffee-growing areas in Brazil. She finds that school enrollment tends to be negatively correlated with the value of coffee production. In regions where coffee is economically important, a decrease of 10 percent in the value of coffee production increases the probability of enrollment for low- and middleincome children by between 3 and 4 percent, while the school enrollment of high-income children is unaffected. Kruger concludes that the substitution effect dominates the income effect when there are temporary changes in local economic conditions in coffee-growing areas in Brazil.

In sum, in five countries in Latin America for which careful analysis has been done, there is little evidence that school enrollment systematically declined during aggregate economic contractions. Enrollment rose markedly during recessions in Mexico and Nicaragua, and marginally in Peru and Brazil. Only in Costa Rica did school enrollment behave procyclically. Nor does it appear that school attainment suffered: in Peru, children who were exposed to the crisis of the late 1980s had completed more years of schooling for their age than comparable children who were not exposed, while even in Costa Rica school attainment appears to have been unaffected by the economic contraction, despite the decline in enrollment at that time.

Much less is known about the effects of aggregate income shocks on the quality of education and about how, if at all, any possible changes in quality affected the labor market performance of cohorts who received their education during crisis years. In Peru, public recurrent expenditures on education dropped sharply between 1987 and 1990, by approximately 50 percent (Schady 2004). Recurrent expenditures are largely made up of teacher salaries, which were severely eroded by the hyperinflation of the late 1980s. The quality of instruction may have deteriorated during the crisis-for example, if there was a higher incidence of teacher absenteeism (although outside options for teachers would also have diminished in the economic downturn) or if teachers were less motivated. Understanding the impact of crises on the quality of education, as opposed to enrollment levels, is an important priority for future research. ${ }^{11}$

We now turn to evidence of the effects of shocks on schooling outcomes in countries outside Latin America, including Indonesia, Côte d'Ivoire, and Malawi. The economic crisis of 1998 in Indonesia was a sudden reversal of fortune for a country that had enjoyed high growth rates for decades. In 1998 GDP per capita contracted by 14 percent, and by a further 1 percent in 1999. Since then growth has resumed, although at rates generally lower than those enjoyed by the country in the decade or so before the crisis. 
Table 3. The Impact of the 1998 Indonesian Crisis on School Enrollment

\begin{tabular}{|c|c|c|c|c|c|c|}
\hline \multirow{2}{*}{ Age } & \multicolumn{3}{|c|}{ Boys } & \multicolumn{3}{|c|}{ Girls } \\
\hline & 1997 & 1998 & Change & 1997 & 1998 & Change \\
\hline 7 & 86.0 & 86.8 & 0.8 & 88.4 & 87.6 & -0.8 \\
\hline 8 & 94.5 & 93.8 & -0.7 & 94.9 & 94.5 & -0.4 \\
\hline 9 & 96.2 & 95.8 & -0.4 & 96.7 & 96.0 & -0.7 \\
\hline 10 & 96.5 & 95.6 & -0.9 & 96.7 & 96.2 & -0.5 \\
\hline 11 & 96.2 & 95.7 & -0.5 & 96.8 & 96.4 & -0.4 \\
\hline 12 & 92.8 & 91.8 & -1.0 & 92.6 & 92.6 & 0.0 \\
\hline 13 & 86.4 & 85.2 & -1.2 & 85.8 & 84.7 & -1.1 \\
\hline 14 & 78.8 & 78.5 & -0.3 & 77.0 & 77.7 & 0.7 \\
\hline 15 & 68.6 & 68.2 & -0.4 & 67.6 & 69.2 & 1.6 \\
\hline 16 & 60.6 & 61.0 & 0.4 & 58.9 & 60.4 & 1.5 \\
\hline 17 & 49.2 & 52.5 & 3.3 & 48.8 & 50.7 & 1.9 \\
\hline 18 & 39.6 & 40.5 & 0.9 & 35.5 & 36.1 & 0.6 \\
\hline \multirow[t]{3}{*}{19} & 26.4 & 27.7 & 1.3 & 21.0 & 22.3 & 1.3 \\
\hline & \multicolumn{3}{|c|}{ Richest quartile } & \multicolumn{3}{|c|}{ Poorest Quartile } \\
\hline & 1997 & 1998 & Change & 1997 & 1998 & Change \\
\hline 7 & 81.7 & 78.9 & 2.8 & 56.5 & 54.6 & -1.9 \\
\hline $8-9$ & 98.8 & 99.2 & -0.4 & 92.1 & 90.6 & -1.5 \\
\hline $10-11$ & 98.9 & 99.2 & -0.3 & 94.2 & 92.8 & -1.4 \\
\hline $12-13$ & 96.5 & 96.2 & 0.3 & 83.5 & 82.2 & -1.3 \\
\hline $14-15$ & 89.2 & 88.7 & 0.5 & 58.4 & 59.6 & 1.2 \\
\hline $16-17$ & 77.0 & 78.6 & -1.6 & 33.5 & 33.9 & 0.4 \\
\hline $18-19$ & 50.7 & 54.1 & -3.4 & 15.1 & 15.4 & 0.3 \\
\hline
\end{tabular}

Source: Thomas and others (2004).

Thomas and others (2004) analyze the impact of the crisis on schooling outcomes. Table 3, based on their results, shows that there was a decrease in enrollment during the crisis, although the estimated changes are very small. ${ }^{12}$ For no age group between 7 and 17 did school enrollment fall by more than 1.2 percent. Even among households in the lowest quartile of the distribution of per capita expenditures, changes in enrollment rates never exceed 2 percent; for most ages, changes were substantially smaller than this.

A different picture emerges from Jensen's (2000) analysis of the effects of drought on school enrollment in Côte d'Ivoire. Jensen uses panel data for 198687 to compare children in villages that were affected by drought and others that were not. ${ }^{13}$ He shows that, between 1986 and 1987, school enrollment of boys grew by 5 percentage points in villages that were not affected by droughts, while the school enrollment of girls grew by 10 percentage points; in contrast, in villages that were affected by droughts, the school enrollment of boys fell by 
14 percentage points, while that of girls fell by 11 percentage points. The implied negative difference-in-difference effects of the drought on school enrollment are quite large, on the order of 20 percentage points. ${ }^{14}$ Similar negative effects of weather shocks on child schooling are reported elsewhere in Africa. In Malawi in 1994-95, a rainfall shock of 10 percent below the long-run average was associated with an increase of 23 percent in the fraction of students who missed two or more consecutive weeks of instruction in the last 12 months, with the largest effects concentrated among children in the poorest households (World Bank 2007).

How does the evidence just reviewed compare with the testable predictions of the framework described in the previous section? All else being equal, the theory would lead us to expect investments in schooling to behave counter-cyclically in richer countries and in those with better developed credit systems, but procyclically in poorer countries and in those where access to credit is severely limited. In addition, deeper, more prolonged crises are more likely to have negative effects on schooling than shorter ones. To summarize the pattern of effects across countries, table 4 reports per capita GDP levels at the time of the crisis, in PPP 2005 US dollars, the magnitude of the shock, and the effect it had on school enrollment. ${ }^{15}$ (No comparable data are available on the development of the financial sector in these countries, although it is likely to be highly correlated with per capita income levels.)

Table 4 shows that Argentina, Brazil, and Mexico had the highest income levels at the time their economies went into recession. Consistent with the framework in the previous section, schooling outcomes in these countries were counter-cyclical-they behaved in a fashion similar to those in the United States. Insofar as there was an income effect of the recession on schooling, it was dominated by the substitution effect. On the other hand, Malawi and Cote d'Ivoire were the poorest countries in the table. Here, the income effect appears to have dominated the substitution effect, with school enrollment behaving in a procyclical manner. ${ }^{16}$ Peru and Indonesia lie somewhere in the middle - the effects of their economic crises on school enrollment were generally small.

Costa Rica and Nicaragua are somewhat harder to explain. In Costa Rica, there was a reduction in school enrollment in spite of the fact that per capita income levels at the time of the crises were reasonably high (similar to Peru), although enrollment appears to have recovered quickly. Nicaragua saw an increase in school enrollment during the period of the coffee crisis in spite of the fact that it is a poor country, more closely comparable in its GDP levels to Cote d'Ivoire than to the other countries in the table. This may be explained, however, by the fact that the magnitude of the negative shock in Nicaragua was smaller than in Costa Rica or Peru, leading to a smaller negative income effect. 
Table 4. The Impact of Various Macroeconomic Crises on School Enrollment

\begin{tabular}{|c|c|c|c|c|c|}
\hline Country & Year of crisis & $\begin{array}{l}\text { GDP in last } \\
\text { year before } \\
\text { crisis }\end{array}$ & $\begin{array}{l}\text { Size of shock (in percent } \\
\text { cumulative contraction } \\
\text { in per capita GDP) }\end{array}$ & Size of shock (other outcomes) & $\begin{array}{l}\text { Change in } \\
\text { enrollment } \\
\text { (sign) }\end{array}$ \\
\hline \multirow[t]{2}{*}{ Brazil } & $1981-83$ & 7,630 & 13.3 & & + \\
\hline & $1990-92$ & 7,691 & 8.4 & & \\
\hline \multirow[t]{3}{*}{ Mexico } & $1982-83$ & 10,037 & 9.0 & $\begin{array}{l}21.7 \text { percent contraction in real } \\
\text { wages }\end{array}$ & + \\
\hline & 1986 & 9,313 & 5.7 & & \\
\hline & 1995 & 9,809 & 7.9 & & \\
\hline Argentina & $1998-2002$ & 10,974 & 21.7 & & + \\
\hline Peru & 1988-92 & 6,223 & 29.8 & $\begin{array}{l}50 \text { percent contraction in per } \\
\text { capita consumption (Lima) } \\
80 \text { percent contraction in real } \\
\text { wages (Lima) } \\
7,500 \text { percent inflation }\end{array}$ & + \\
\hline $\begin{array}{r}\text { Costa } \\
\text { Rica }\end{array}$ & $1980-82$ & 6,158 & 14.3 & $\begin{array}{l}50 \text { percent contraction in real } \\
\text { wages }\end{array}$ & - \\
\hline Nicaragua & $2000-02$ & 2,357 & & $\begin{array}{l}27 \text { percent contraction in per } \\
\text { capita consumption (coffee- } \\
\text { growing areas) }\end{array}$ & + \\
\hline Indonesia & 1998 & 3,087 & 14.3 & & - \\
\hline $\begin{array}{l}\text { Côte } \\
\text { d'Ivoire }\end{array}$ & $1986-87$ & 2,147 & & & - \\
\hline Malawi & $1994-95$ & 653 & & & - \\
\hline
\end{tabular}

Note: GDP levels are GDP per capita, PPP (constant 2005 international US\$).

Source: World Bank (2008).

\section{Child Health and Nutrition}

We next turn to the effects of aggregate economic shocks on child health and nutrition. As with the evidence on schooling, there are a reasonable number of studies from developing countries to draw on. A handful of these refer to Latin America, including Paxson and Schady (2005) on Peru, Cutler and others (2002) on Mexico, Maluccio (2005) on Nicaragua, and Miller and Urdinola (2007) on Colombia. Other country-specific studies that consider the impact of aggregate economic shocks on health outcomes include Stillman and Thomas (2004) on Russia; Frankenberg, Thomas, and Beegle (1999), Rukumnuaykit (2003), and Strauss and others (2004) on Indonesia; and Bhalotra (forthcoming) on India. We also discuss findings from a recent study that uses demographic and health surveys (DHS) ${ }^{17}$ to analyze the effect of positive and negative aggregate income shocks on infant mortality for 59 developing countries (Baird, Friedman, 
and Schady 2007). Finally, we review the evidence of the effects of droughts on child nutritional status in Africa, including Hoddinott and Kinsey (2001) and Alderman, Hoddinott, and Kinsey (2006) on Zimbabwe; Yamano, Alderman, and Christiaensen (2005) on Ethiopia; Alderman, Hoogeveen, and Rossi (2009) on Tanzania; and Jensen (2000) on Côte d'Ivoire.

As with schooling, it is useful to begin by briefly reviewing the literature on the United States. A series of papers by Ruhm (2000, 2003, 2005, 2007) and Ruhm and Black (2002) argue that adult health status tends to improve during recessions in the United States. In part, this appears to be a result of increases in the fraction of adults who regularly exercise during recessions and decreases in the corresponding fractions who smoke, drink excessively, and eat unhealthy foods. ${ }^{18}$ Turning to child health, Chay and Greenstone (2003) and Dehejia and Lleras-Muney (2004) both document counter-cyclical patterns in infant mortality, with more babies dying during economic expansions.

Chay and Greenstone (2003) show that pollution falls during recessions. Using variation over time and across counties in pollution levels, they show that lower pollution levels, in turn, results in fewer infant deaths. Dehejia and Lleras-Muney (2004) use state-level data to show a decrease in the incidence of low and very low birth-weight babies and in infant mortality during recessions, especially among children born to black women. Part of the explanation for these patterns is that there are changes in the composition of women giving birth, with significant reductions in the fraction of black mothers who are high-school dropouts during recessions. This is consistent with black high-school dropouts being more credit constrained than more educated black women; black women with less education therefore choose to have children during economic expansions, when incomes are higher, despite a higher opportunity cost of childbirth. When they consider changes in behaviors that might explain the differences in infant mortality rates, Dehejia and Lleras-Muney (2004) find that (both black and white) mothers have more prenatal care visits during recessions. The authors conclude that child health improvements during recessions in the United States are driven both by changes in the composition of the pool of mothers and by behavioral "improvements".

In contrast with the literature from the United States, the evidence on developing countries-including middle-income countries, such as those in Latin America-suggests that child mortality is counter-cyclical, decreasing in booms and increasing in crises. Paxson and Schady (2005) analyze the effects of the crisis of the late 1980s in Peru on infant mortality using DHS data. They show that the crisis coincided with a large spike in infant mortality-from 50 to 75 per 1,000 children born. Using these estimates they calculate that the crisis resulted in approximately 18,000 "excess" deaths-deaths that would not have taken place without the economic crisis. ${ }^{19}$ 
Paxson and Schady (2005) make two other points. First, they show that the increase in mortality was not a result of possible changes in the composition of women giving birth. ${ }^{20}$ Second, they show that the crisis came hand in hand with a dramatic collapse in public expenditures on health, which fell from approximately 80 Peruvian soles per capita in 1988 to 30 soles in 1990. Using the DHS data, Paxson and Schady also show declines in health service utilization by households during the crisis years, including a higher fraction of home births and fewer antenatal check-ups. They conclude that the health sector collapse may be part of the explanation for the spike in infant mortality. We return to this point below.

Cutler and others (2002) use vital registration data to analyze the effects of economic contractions on mortality in Mexico between 1980 and $1998 .^{21}$ They focus on three crisis periods, corresponding to $1982-84,1985-89$, and 199496. To quantify the impact of these crises on the mortality of vulnerable groups, in particular children (age 0-4) and the elderly (age 60+), they assume that the mortality of prime-age males, age 30-44, was unaffected by the crises. They then compare changes in mortality among children and the elderly before and during the crisis with the corresponding changes in mortality among prime-age males. Based on this difference-in-differences estimation strategy, they conclude that the three crisis periods resulted in increases in child mortality of 9.2 percent (198284 crisis), 10.3 percent (1985-89), and 6.9 percent (1994-96). Using a similar approach, they also report increases in the mortality of the elderly, ranging from 2 to 8 percent. $^{22}$

Two papers look at the impact of sudden changes in the price of coffee on child health and mortality in coffee-growing areas. The first of these, by Maluccio (2005), discusses the impact of the sharp reduction in the price of coffee between 2000 and 2002 on child nutritional status in coffee-growing areas in Nicaragua. Maluccio shows that the coffee price shock, and the attendant reduction in living standards, came hand in hand with a decline in the height-for-age $z$-score of children aged 6 to 48 months of 0.15 points, although the coefficient is only borderline significant. $^{23}$

The results for Mexico and Nicaragua, like those for Peru, suggest that the reduction in public and private expenditures on health-promoting goods dominates any positive effects of downturns in terms of more time for child care and lower consumption of health-reducing goods like cigarettes and tobacco in Latin America. This is not the case in the analysis by Miller and Urdinola (2007) of the impact of three sudden changes in the price of coffee on infant mortality in coffee-growing areas in Colombia. ${ }^{24}$ Miller and Urdinola use population census data to analyze changes in the size of birth cohorts between the year immediately before a coffee price shock and the year of the shock itself. Implicitly, this assumes that the price shocks did not have an effect on the mortality of older children. 
The analysis also exploits differences between coffee-growing municipalities and other municipalities. The estimation strategy is therefore difference-in-differences (across municipalities and over time). Based on this, Miller and Urdinola conclude that infant mortality is procyclical-increasing when there are positive price shocks (and therefore higher incomes in coffee-growing areas) and decreasing when shocks are negative. This pattern of results is similar to that found in the United States - see the discussion of Dehejia and Lleras-Muney (2004) above. However, the magnitude of the coefficients reported by Miller and Urdinola is very large, perhaps implausibly so. ${ }^{25}$

We turn next to evidence from developing countries outside Latin America. Stillman and Thomas (2004) analyze the impact of an economic contraction in Russia in 1998 on household expenditures on food, food intake, and measures of nutritional status-including Body Mass Index (BMI) for adults and height-forage and weight-for-height for children. The 1998 crisis analyzed by Stillman and Thomas was particularly deep, involving a 30 percent contraction in GDP in the last two quarters of 1998 , and an 18 percent decrease in per capita expenditures; however, the recovery was also quick - by 2000, income levels were back to their pre-crisis levels.

Stillman and Thomas (2004) use a rich data set that includes measures of expenditures as well as nutrient intake, as reported by households for 24-hour recall periods. They show that total expenditures on food dropped sharply during the crisis. When they consider the impact of the crisis on the quantities of various foodstuffs consumed, however, the results are more nuanced. For starches, meats, and dairy products, the crisis did not result in a decrease in the quantity consumed-rather, it seems, households switched from more expensive to less expensive sources of calories within these food categories. Only in the case of consumption of fruits and vegetables is there clear evidence of a sharp decrease during the crisis and of a rebound thereafter. Despite this resilience in total caloric intake, however, there is some evidence of a deterioration in the nutritional status for children-estimates of the effect of the transitory shock to income on the weight-for-height $z$-score suggest a decline of about 0.11 points. On the other hand, there is no evidence of a deterioration in height-for-age, a more long-run measure of child nutritional status.

A number of authors have studied the impact of the 1998 crisis in Indonesia on child health and nutrition, with mixed results. Strauss and others (2004) show that there is no evidence that weight-for-height, height-for-age, or blood hemoglobin levels were negatively affected by the crisis-see also Frankenberg, Thomas, and Beegle (1999). Of the child health outcomes they study, only mother-reported child health status appears to have worsened significantly. On the other hand, there is some evidence that infant mortality spiked up sharply, from about 30 per 1,000 in 1996 to 48 per 1,000 in 1998 (Rukumnuaykit 
2003; see also Simms and Rowson 2003, who argue that infant mortality increased between 1996 and 1999 in 22 of Indonesia's 26 provinces). ${ }^{26}$

An important issue with regard to the Indonesian crisis is that expenditures on health appear to have been protected from sharp cuts. This point is made in figure 1, which shows that although Government health expenditures contracted during the crisis, by about 20 percent, much of this shortfall was made up by donor assistance to the health sector, which increased sharply. This pattern of expenditures may help explain why, with the possible exception of infant mortality, child health outcomes do not appear to have suffered much. Figure 2 shows that, by contrast, public health expenditures in Peru fell by more than half, and there is no evidence that these shortfalls were made up from other sources, including donor assistance.

Health outcomes appear to have deteriorated during economic contractions in most other developing countries. In a study using DHS data for India, Bhalotra (forthcoming) analyzes the effects of aggregate income shocks on infant mortality. Methodologically, the approach is similar to that followed by Paxson and Schady (2005) in their analysis for Peru. However, Bhalotra arguably has better data and a more credible identification strategy because she exploits differences across states in GDP growth rates and in the magnitude and timing of deviations from GDP trends, rather than simply using national averages. She concludes that there is no clear pattern of effects in urban areas. In rural areas, however, infant mortality appears to be counter-cyclical-as in Peru, Mexico, and Indonesia. The magnitude of her estimates implies that a negative income shock of median size in the data is associated with an increase in mortality of approximately 0.14 percentage points, which is almost half the annual linear decline in rural mortality in India over the period she studies. Moreover, when she disaggregates her findings by gender, Bhalotra finds that boys are fully protected from income shocks - only the mortality of girls rises during aggregate shocks. Finally, Bhalotra shows that high-risk women were more likely to postpone childbearing during aggregate downturns in India, and she controls for this by using mother fixed effects. (These compositional changes are similar to those found by Dehejia and Lleras-Muney among black women in the United States.)

Pongou, Salomon, and Ezzati (2006) focus on the effects of the macroeconomic decline in Cameroon between 1991 and 1998. They show that this decline was associated with an increase in weight-for-age malnutrition, which increased by 9 percentage points for boys and 3 percentage points for girls. Increases in malnutrition were larger among children of mothers with no education than those with primary schooling, and larger for mothers with primary schooling than those with secondary schooling; they were also larger in rural areas than in urban areas, and among households with few assets. 
Figure 1. Public Expenditures on Health During the Crisis: Indonesia

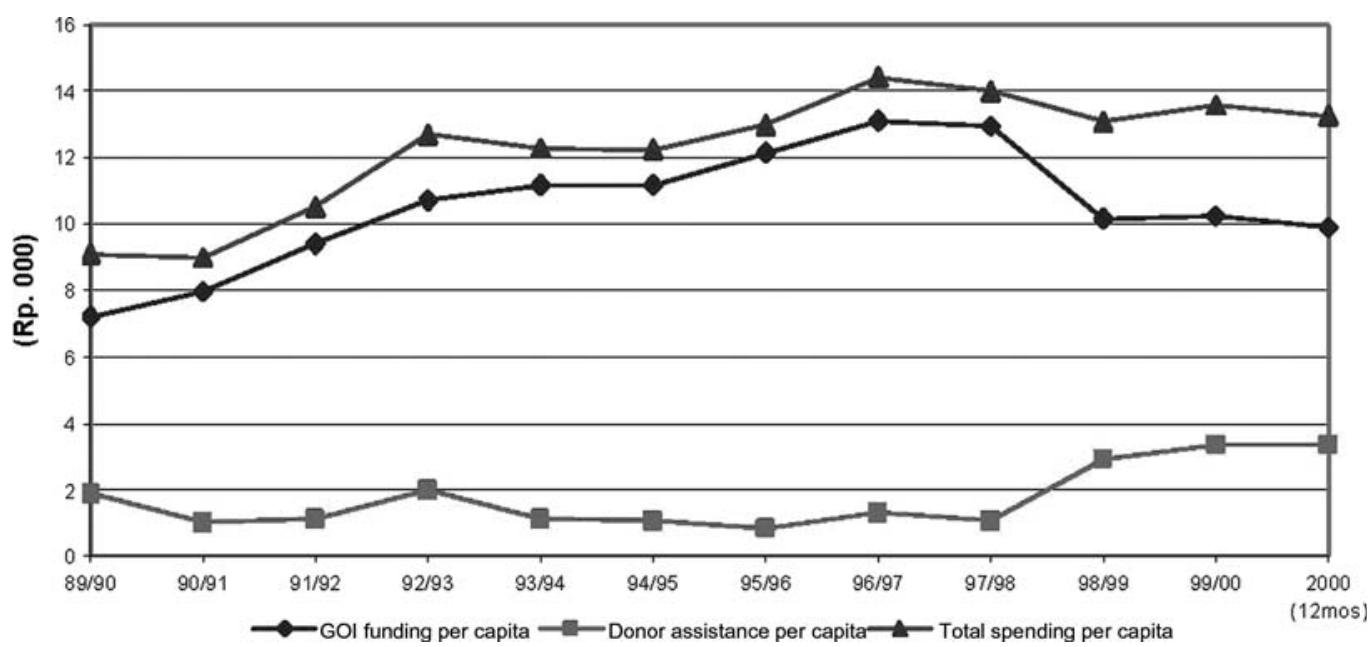

Source: Lieberman, Juwono, and Marzoeki (2001) 
Figure 2. Public Expenditures on Health During the Crisis: Peru

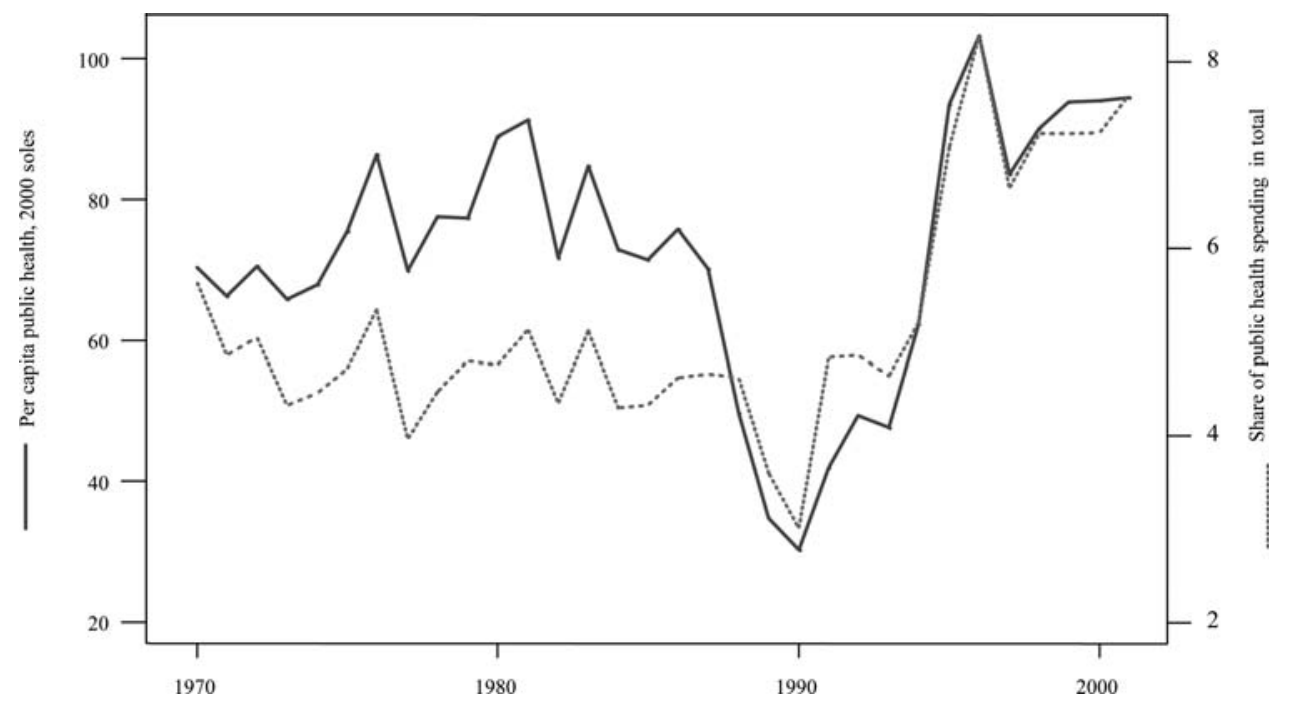

Source: Paxson and Schady (2005).

Finally, Baird, Friedman, and Schady (2007) use data from DHS covering 59 developing countries and approximately 1.7 million births. On the basis of these data they construct country-specific infant mortality series and merge these with data on per capita GDP. After flexibly removing country-specific trends in the infant mortality and GDP series, they show that income shocks have large negative effects on infant mortality: a 1 percent decrease in per capita GDP is associated with an increase in infant mortality of between 0.31 and 0.79 percent.

Baird, Friedman, and Schady (2007) present various extensions to this basic finding. First, they include mother fixed effects in their regressions and show that changes in infant mortality are apparent even after accounting for the changing composition of women giving birth - the estimates that include fixed effects are very close in magnitude to those that do not. Second, they merge their data with data on weather shocks (droughts and floods) and conflicts, and show that the association between changes in per capita GDP and changes in infant mortality is unaffected by the inclusion of these additional controls. This is important as weather shocks and conflict could have independent effects on mortality above and beyond their effects on aggregate incomes. Finally, they argue that there are important asymmetries in the relationship between GDP shocks and infant mortality. Figure 3, reproduced from their paper, presents the results of nonparametric regressions of the infant mortality rate on the logarithm of per capita GDP, 
Figure 3. Income Shocks and Infant Mortality in the Developing World

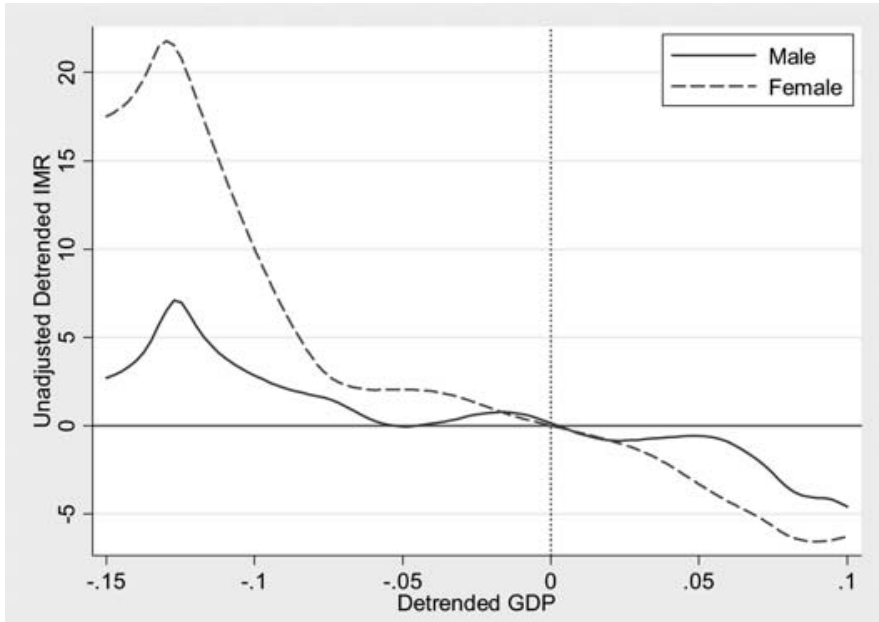

Notes: These are locally weighted least-squares regressions of the infant mortality rate (IMR), per 1,000 live births, on the logarithm of per capita GDP. Country-specific cubic trends have been removed from both series.

Source: Baird, Friedman, and Schady (2007).

separately for boys and girls, after country-specific cubic trends have been removed from both time series. The units on the vertical axis correspond to the number of infant deaths per 1,000 children born, while those on the horizontal axis correspond (approximately) to percentage changes in per capita GDP. The picture shows that positive income shocks tend to imply quantitatively small improvements in infant mortality, even when these shocks are large; moreover, these improvements in income affect the likelihood of survival for boys and girls in a similar way. On the other hand, negative income shocks have much larger effects on infant mortality, especially for girls, and especially for the largest shocks. Using the coefficients from the regressions in their paper, Baird, Friedman, and Schady report the results from some back-of the-envelope calculations. These suggest that more than 1 million excess deaths occurred in the developing world during 1980-2004 in countries experiencing economic contractions of 10 percent or greater, with the bulk of these deaths found among girls.

In many parts of the world, such as Africa, aggregate income fluctuations are often caused by weather shocks, and we discuss the findings from a substantial body of research that has studied the effect of droughts on child nutrition in Africa. ${ }^{27}$ We begin by discussing two papers on Zimbabwe (Hoddinott and Kinsey 2001; Alderman, Hoddinott, and Kinsey 2006). Using five rounds of panel data, 
Hoddinott and Kinsey show that children who were 12-24 months during a drought in 1995-96 grew by approximately 1 centimeter less than other children in this age range in nondrought years. When they control for a variety of child and household characteristics, the coefficient on drought exposure among young children increases, implying a deceleration in growth of approximately 1.7 centimeter. They also show that children in older age groups do not appear to experience a similar growth slowdown, consistent with the nutritional literature which suggests that children are particularly vulnerable to nutritional insults between weaning and the second birthday (Martorell 1999; Shrimpton and others 2001).

Alderman, Hoddinott, and Kinsey (2006) focus on the effects of a two-year drought in 1982-84 and on the civil war in Zimbabwe prior to 1980. They first show that children who were exposed to the drought had lower growth trajectories than other children-consistent with the results in Hoddinott and Kinsey (2001). Similar results also hold for exposure to the civil war, which resulted in significantly lower height-for-age. Alderman, Hoddinott, and Kinsey then show that children who were shorter as a result of exposure to the drought or civil war do not make up these growth deficits later on: they become shorter adolescents. Further, they start school later and attain fewer years of schooling.

Negative effects of droughts on child nutritional status are also reported elsewhere in Africa. Jensen (2000) shows that drought exposure is associated with an increase of 3.5 percentage points in the fraction of children with weight-forage more than two standard deviations below the international norm (from a base of approximately 5 percent). Yamano, Alderman, and Christiaensen (2005) estimate that a 10 percentage point increase in the proportion of plots that are damaged by drought is associated with a decline in child growth rate of approximately 0.12 centimeter over a six-month period in Ethiopia. Alderman, Hoogeveen, and Rossi (2009) use a panel extending for more than 10 years in the Kegara region of Tanzania to show that children who experienced weather shocks in early childhood were more likely to have low height-for-age, start school late, and have completed fewer years of schooling in adolescence. They use various simulations to show that this, in turn, translates into substantial reductions in earnings in adulthood.

Finally, Dinkelman (2008) focuses on the effects of a severe drought in southern Africa in the early 1980s. Using a high-quality panel data set, the cape area panel study (CAPS), ${ }^{28}$ she exploits variation in drought intensity related to birth timing and birth location to identify the effects of the drought on a variety of measures of education and health status. Based on this difference-in-difference identification strategy, Dinkelman finds that "drought babies" grow to be substantially shorter than other children and perform substantially worse on various measures of cognitive ability in adolescence. Unexpectedly, she finds that these negative effects of the drought are only apparent among boys, not girls. She 
provides some evidence that the reason for these surprising differences by gender may be biological, namely, that male infants are weaker at birth and therefore more susceptible to the effects of nutritional deprivation.

Although much of the literature on the effects of droughts on investments in early childhood has focused on Africa, we close with a discussion of a recent paper by Maccini and Yang (forthcoming) that uses data from Indonesia. Maccini and Yang match health, education, and labor market outcomes for adults in a recent round of the Indonesian family life survey ${ }^{29}$ with locality-specific rainfall for their birth year. Their results suggest substantial effects of rainfall in the first year of life on adult outcomes for women, but not for men. Women who were born in localities with higher rainfall have better self-reported health status, are taller, and have completed more years of schooling; these women had also accumulated more assets in adulthood. The coefficients for comparable regressions for men are never significant, suggesting that, in Indonesia, investments in boys are better protected from income fluctuations than investments in girls. These gender differences are reminiscent of the asymmetric effect of recessions on infant mortality reported by Baird, Friedman, and Schady (2007). ${ }^{30}$

To summarize, the picture on the effects of economic shocks on child health seems empirically clearer than that for schooling outcomes. In rich countries (effectively, in our sample of studies, for the United States), health status is counter-cyclical (that is mortality and morbidity fall during recessions). In developing countries, on the other hand, child health is procyclical (that is, infant mortality and malnutrition increase during recessions). The only exception to this pattern, among the studies we have surveyed, are the results in Miller and Urdinola (2007) on procyclical infant mortality in Colombia.

\section{Conclusions And Policy Implications}

The simple framework outlined in this paper suggests that the effect of aggregate economic shocks on child health and education outcomes is theoretically ambiguous - and therefore that we should expect it to vary across countries and episodes. But the framework also suggests some elements of how it should be expected to vary.

Richer countries, and those with deeper and better-functioning credit markets, are more likely to see improvements in both health and education during downturns. School enrollment increases because the income effect of a crisis is weaker for initially richer countries and for households with greater access to credit markets, leading to a dominance of the "pro-schooling" substitution effect. Health improves because the marginal product of public and private expenditures in health is lower in rich countries and households, relative to the health 
contribution of additional parenting time (and, in some cases, because of lower consumption of goods with negative health consequences during downturns).

In the poorest countries, we would expect to see exactly the opposite pattern: education and health outcomes should be procyclical, with things getting worse in recessions. Middle-income countries should fall somewhere in-between, and the resolution of the (different) trade-offs in health and education are an empirical matter. The review of the literature carried out is supportive of the predictions for rich and poor countries-largely the United States at one extreme, and Africa and a few low-income Asian countries at the other. It is also informative of the empirical outcomes for middle-income countries, largely in Latin America. Table 5 provides a schematic summary of these findings.

As table 5 illustrates, recessions, droughts, and other economic downturns tend to have negative effects on both health and education outcomes for children in poor countries. This was apparent for school enrollment and child health in a variety of African countries. To some extent, the picture that emerges for Indonesia during the 1998 crisis is similar, although the magnitude of the negative effects is much smaller-perhaps because Indonesia was wealthier than the African countries that were analyzed, or perhaps because public expenditures on education and health were better protected in Indonesia. At the other end of the spectrum, economic downturns appear to be robustly associated with improvements in child health and education outcomes in the United States.

Between those two extremes in the income scale, there lies a middle-income range populated (not exclusively) by a number of Latin American countries. In this intermediate range, results are different for health and for education. In practice, with the exception of the results for Colombia, health outcomes in Latin America appear to be procyclical-worsening during recessions. This was also the case in Russia in 1998, at least with regard to child weight-for-height. In contrast, with the exception of the results for Costa Rica, education outcomes appear to be counter-cyclical in middle-income countries-improving during recessions.

There is also evidence that these effects are heterogeneous not only across but also within countries. This heterogeneity manifests itself along a number of dimensions. One of them is gender: a number of studies have found that negative economic shocks have worse effects for the mortality and health of girls (Bhalotra forthcoming on India and Baird, Friedman, and Schady 2007 on a large sample of developing countries), although this pattern is not apparent everywhere (see Dinkelman 2008 on South Africa). There is also heterogeneity by race, as in the Dehejia and Lleras-Muney (2004) study of the United States. A third dimension is geographic and occupational (or both), with children in coffee-growing areas in Nicaragua experiencing a greater increase in enrollment as a result of a negative price shock than those where other economic activities dominate (Maluccio 2005). 
Table 5. The Expected Effect of a Negative Aggregate Economic Shock on Child Health and Education Outcomes

\begin{tabular}{|c|c|c|}
\hline & Education outcomes & Health and nutrition outcomes \\
\hline \multirow[t]{2}{*}{ Rich countries } & Positive impact & Positive impact \\
\hline & - United States & - United States \\
\hline \multirow[t]{6}{*}{ Middle-income countries } & $\begin{array}{l}\text { Ambiguous impact } \\
\text { Examples of positive impact }\end{array}$ & $\begin{array}{l}\text { Ambiguous impact } \\
\text { Examples of positive impact }\end{array}$ \\
\hline & - Mexico & - Colombia \\
\hline & $\begin{array}{l}\text { - Brazil } \\
\text { - Argentina }\end{array}$ & Examples of negative impact \\
\hline & - Peru & - Peru \\
\hline & Examples of negative impact & $\begin{array}{l}\text { - Mexico } \\
\text { - Russia }\end{array}$ \\
\hline & - Costa Rica & \\
\hline
\end{tabular}

Poor countries

Negative impact

Negative impact

- Indonesia

- Côte d'Ivoire

- Malawi

- South Africa

- (Nicaragua)
- Nicaragua

- India

- Côte d'Ivoire

- Zimbabwe

- Ethiopia

- Tanzania

- Cameroon

- South Africa

Note: Parentheses indicate the reverse effect, for countries that deviate from the theoretical predictions.

Finally, there is evidence of heterogeneity by socioeconomic status. In Cameroon, households with fewer assets experienced a greater increase in malnutrition between 1991 and 1998 (Pongou, Salomon, and Ezzati 2006). In middleincome countries in Latin America, there appear to be larger increases in school enrollment during economic downturns among poorer households (Schady 2004; Kruger 2007). This is similar to evidence for the United States-for example, Kane (1994) shows that the college enrollment decisions of blacks, who are on average poorer than whites, tend to be more strongly counter-cyclical with respect to average earnings in manufacturing than those of whites. This is 
consistent with the substitution effect being relatively more important for poorer households.

Does this analysis have any implications for policy? It is hard to extrapolate the lessons from this (or any other) literature review to any particular country that may be exposed to aggregate shocks in the future without a careful effort to understand the specific circumstances of the country in question. Nevertheless, to the extent that this paper reveals the empirical regularities summarized above, four general implications are worth highlighting.

First, education and child health outcomes do not respond to shocks in the same way everywhere. If an international institution sought to allocate a certain budget so as to minimize the decline in enrollment (or the increase in infant mortality) across a number of countries of very disparate income levels, then it might consider an allocation that is biased toward the poorest countries and those that have the least developed credit markets. The evidence suggests that human capital investments in these countries suffer most from aggregate shocks.

Second, in a developing country that suffers from a negative income shock, our analysis provides yet another reason (if one were needed) why a government allocating resources to different population groups might consider targeting these to the poor. These households are more likely to be credit constrained, and the disutility of reductions in consumption is likely to be larger. They are, therefore, most likely to engage in "destructive" behaviors (from the point of view of investments in child human capital), such as taking children out of school or curtailing expenditures on health-promoting inputs.

Third, in a middle-income country that suffers a negative aggregate shock, if a government or agency sought to allocate a given budget between the education and health sectors so as to protect the human capital of children, a presumption might be justified to favor health rather than education. The evidence suggests that in middle-income countries like those in Latin America recessions harm child education much less often than they harm child health.

Finally, the conceptual framework suggests that one way in which the effect of crises on outcomes can be mitigated (across all countries) is a protection of public expenditures in the supply of health and education services. Such expenditures make services more attractive by preserving quality. That simple framework and the review of the evidence in this paper are not sufficient to yield general policy recommendations on the composition of that expenditure, with one possible exception. That exception is the nature of public expenditure on education in middle-income (say, Latin American) countries, during moderate downturns.

The evidence suggests that, in these circumstances, the substitution effect of falling child wages tends to outweigh the income effects of the recession, leading to increased demand for schooling. In this light, reductions in the quality of education services would appear to represent a greater threat to enrollment, 
attainment, and achievement than falling demand. The implication is that countries should carefully consider whether expenditures that protect the supply side of the educational system, such as by preserving the real salaries of teachers and continuing to invest in schools, are not more important than expenditures aimed at further buttressing demand, such as CCTs. Cash transfers might, of course, need to be increased for a variety of reasons during a recession. And it may be that an existing CCT scheme provides the most cost-effective means for a social protection system to respond rapidly to a crisis. But those, rather than a misperceived need to support the demand for schooling during downturns, should be the grounds on which a CCT is preferred over alternative expenditures.

\section{Funding}

Funding from the World Bank's Research Support Budget for the "Equity and Development Research Project” (grant P099861) is gratefully acknowledged.

\section{Notes}

Francisco H. G. Ferreira and Norbert Schady are both in the Research Department at The World Bank; Corresponding authors: fferreira@worldbank.org; nschady@worldbank.org. The authors are grateful to Harold Alderman, Kathleen Beegle, Anna Crespo, Emmanuel Jimenez, David McKenzie, Apurva Sanghi, and three anonymous referees for helpful comments on an earlier version. All errors are our own. The views expressed in this paper are those of the authors and they should not be attributed to the World Bank, its Executive Directors, or the countries they represent.

1. We do not address the impact of idiosyncratic shocks, such as death, illness, or employment loss of the main breadwinner, on the accumulation of human capital of children, for two reasons. First, there is a large separate literature on this subject. Second, the economics of idiosyncratic shocks is substantively different in some important respects. As we discuss in detail below, the effect of aggregate shocks on child schooling and health is a function of income and substitution effects. The substitution effect results from reductions in the opportunity cost of time of children and adults during recessions; this is absent in the case of idiosyncratic shocks. As a result, even within the same country and time period, aggregate and idiosyncratic shocks can have quite different effects on the accumulation of human capital. For example, focusing on Brazil in the 1990s, Duryea and Arends-Kuenning (2003) find that aggregate economic shocks generally result in increases in school enrollment, while Duryea, Lam, and Levison (2007) find that idiosyncratic shocks such as unemployment of the household head generally result in lower school enrollment.

The economic consequences of "slow-onset" natural shocks, such as prolonged droughts, have much in common with those of recessions, and we discuss some examples here. On the other hand, "sudden-onset" natural disasters, such as earthquakes, severe floods, or hurricanes, are arguably different in a number of respects. They may cause sudden and widespread loss of life and destroy large amounts of existing physical and human capital. On the other hand, their effects on relative prices and income flows may or may not be as long lasting. These are different phenomena, and we do not consider them in this paper. Recent examples of the analysis of sudden-onset shocks include Poertner (2008) on the effects of hurricane shocks on educational attainment in Guatemala, and 
del Ninno and Lundberg (2005) on the effects of the 1998 floods in Bangladesh on nutritional status.

2. An example of the presumption that recessions would hurt human capital accumulation rates can be found in the influential volume edited by Lustig (1995). Although she provided a careful and balanced review of the declines in infant mortality and illiteracy rates, as well as of the increases in completed years of schooling, during the recessions of the 1980s in Latin America she nevertheless concluded that "smaller earnings may have led households to postpone their entry into primary school... and young adults to join the workforce instead of continuing their education" (p. 13). The 2000/2001 World Development Report similarly states that "most social indicators either deteriorate or improve at a slower pace during a macroeconomic crisis" (World Bank 2001, p. 164).

3. The basic idea of investment in human capital as a time-allocation decision in an intertemporal utility maximization problem goes back to Becker (1965) and Ben-Porath (1967). The idea was extended in Becker (1991) and applied to a discussion of the efficiency of child labor by Baland and Robinson (2000). Our framework builds on these models.

4. On the other hand, the substitution effect may also be stronger for poorer households if better-off households enroll their children in school no matter what the wage rate. As we discuss below, there is some evidence for developed countries, like the United States, and middle-income countries, like Peru and Brazil, that suggests that the schooling choices of poorer households are more responsive to changes in the opportunity cost of going to school than their better-off counterparts.

5. The negative effect of public spending on private investment in health or education may be compounded by the fact that, in countries where public sector services are seen as inferior to private sector alternatives, a recession is likely to lead to increased demand for the public sector services, as fewer households are able to afford private fees. More customers are then likely to compete for services produced with fewer resources.

6. Binder also conducted an econometric analysis in which school retention and continuation rates in year $t$ are regressed on log GDP levels in the same year, on percentage changes in GDP in the calendar year in which a school year was begun, on percentage changes in GDP in the year in which a school year was finished, and on a time trend. She interpreted the coefficient on log GDP, which tends to be positive and significant in most specifications, as the "income" effect and the coefficient on GDP changes, which tends to be negative and significant in most specifications, as the "price" effect. It should be clear that these definitions of "income" and "price" effect do not correspond to the notions of income and substitution effect which are more commonly used in the literature, and which we adopted in the previous section. In any case, there is no clear pattern whereby the coefficient on log GDP is larger or smaller than the coefficient on GDP changes in Binder's regressions.

7. General information on these surveys can be found at http://enigh.one.gob.do/.

8. Per capita GDP was essentially flat in 1991 and 1992, before beginning a recovery in 1993. Nevertheless, the crisis was so severe that it was not until 2005 that per capita GDP in Peru reached the pre-crisis, 1987 level—despite generally positive growth rates from 1993 onwards.

9. General information can be found at http://econ.worldbank.org/WBSITE/EXTERNAL/EXTDEC/ EXTRESEARCH/EXTLSMS/0, contentMDK:21485765 pagePK:64168445 piPK: $64168309 \sim$ theSitePK:3358997,00.html\#Peru

10. The lack of a crisis effect on school attainment, in spite of the decline in school enrollment, is somewhat puzzling. A number of authors (for example, de Janvry and others 2006) have suggested that, once children have dropped out of school, they are unlikely to re-enroll for the reasons that they have fallen behind their group of class peers and friends and that the opportunity cost of their time will have increased as they age. It is possible that the aggregate results for Costa Rica mask some underlying heterogeneity, with some children exposed to the crisis dropping out of school and completing fewer years of schooling, and others completing more, as appears to have been the case in Peru (Schady 2004).

11. One way to address this question would be to compare the performance of students on standardized tests in different years, but (to our knowledge) no such data are available from a developing 
country spanning the years before, during, and after a major economic recession. Another approach would be to see whether the wage premium paid to adults for each additional year of schooling is lower for those who received their education during the crisis years. We attempted to do this with the Encuesta Nacional de Hogares surveys for Peru. Specifically, using surveys for 2002 and 2007, we traced out the earnings profiles of adults with no schooling, primary schooling, and secondary schooling by calendar year of birth. These graphs have the expected shape-the earnings profiles for workers with more schooling lie above those for workers with less schooling, and the difference between the earnings schedules increases with age. If school quality dropped appreciably during the crisis, we might expect to see a "dent" in the earnings profile of workers with primary school education, relative to those with no education, for cohorts that received their education during the crisis years. Children of primary school age, age 6-11 during the 1988-92 crisis, would have been 16-25 years of age in 2002, and 21-30 years of age in 2007. We see no clear evidence of any crisis patterns, although the estimates tend to be quite noisy, in spite of the reasonably large number of observations in these surveys (56,371 observations in 2002 and 65,549 in 2007). We thank Luis Barrantes for making these data available to us.

12. The authors report percentage changes in school nonenrollment rates. These appear to suggest quantitatively large, negative effects of the crisis. However, because enrollment rates before the crisis were high, a small increase in nonenrollment translates into a large percentage change. When reported as changes in enrollment, the effects appear quite small.

13. He defines villages as having suffered from a drought if rainfall was more than one standard deviation below the historical mean.

14. Although the results in Jensen (2000) are suggestive, the large, positive change in school enrollment rates in a single year in villages that were unaffected by the drought could be a source of concern. Moreover, because data are available for only two periods, Jensen cannot test whether the two groups of villages had different trends in outcomes, including enrollment, prior to the period he analyzes.

15. Note that the studies for Nicaragua (Maluccio 2005) and Côte d'Ivoire (Jensen 2000) refer to rural areas, where incomes are likely to be much lower than in urban areas, so the GDP values in the table for these two countries give a somewhat misleading picture of the welfare of households affected by the crises described in these papers.

16. The cycle of production in agricultural areas may have reinforced the negative income effect in Malawi and Côte d'Ivoire. Rainfall shocks often coincide with the harvest season and result in reductions in household income and consumption. This is the income effect of the shock on child schooling. By the time of the planting season, however, the demand for child labor once again increases, so there is no (pro-schooling) substitution effect. Indeed, if the shock to income is severe enough, the demand for child labor during the planting season may be higher as a result of the drought, as families try to eke out more output from the farm (even if the marginal product of additional child labor is low). We thank Harold Alderman for this point.

17. General information on these surveys can be found at http://www.measuredhs.com/.

18. More recent research suggests that improvements in health status during recessions do not affect all population groups and are not apparent for all health outcomes. For example, Charles and DeCicca (2008) show that mental health deteriorates and obesity increases during recessions, especially for those whose (prerecession) employment status is most marginal.

19. In the working-paper version of their paper, Paxson and Schady (2004) also provide evidence of a deterioration in height-for-age for young children during the crisis.

20. They use Oaxaca-style decompositions to show that changes in the composition of women giving birth along various observable characteristics, such as education and place of residence, are small, and that holding constant these characteristics has little effect on their estimates of infant mortality during the crisis.

21. The use of vital registration data is a source of concern. In most developing countries, including Mexico, under-reporting of deaths is common. Moreover, if, as seems plausible, the coverage of the vital registration system itself changes with aggregate economic conditions, the estimates may be 
systematically biased. For example, if fewer deaths are reported or accurately recorded during bad economic times, the associations reported by Cutler and others (2002) would be downward biased.

22. Additional evidence for the 1994-96 crisis in Mexico reveals that private household expenditures on health care fell more than proportionately at the time (McKenzie 2006). This may be one of the mechanisms behind the pro-cyclical behavior of health indicators in Mexico and is direct evidence in support of the previously discussed income effect on health-producing goods. Interestingly, over the same period private expenditure on education actually rose as a share of total consumption, which is also consistent with a prevalence of the (pro-schooling) substitution effect over the income effect in education.

23. As with the analysis of changes in school enrollment patterns, these numbers refer to children in the control group, who were ineligible for transfers from the Red de Protección Social.

24. These three price shocks correspond to a frost which devastated the coffee crop in Brazil in 1975 and resulted in an increase in coffee prices in Colombia of more than 50 percent; a severe drought in Brazil in 1985, which also led to increases in the price of coffee in Colombia of more than 50 percent; and the collapse of the International Coffee Agreement among producer countries in 1990, which resulted in a decrease in coffee prices in Colombia by approximately one-third.

25. The infant mortality rate in Colombia in 1980 was approximately 37 per thousand children born (World Bank 2008). In the main table of results in Miller and Urdinola (2007, table 2), the authors report the effects of the three price-change events they study, at the median coffee-growing intensity and for a 500 peso price change. These imply a change in cohort size of between 0.40 and 2.89 percent or, equivalently, between 4 and 29 fewer (more) cohort members per thousand people born. This, in and of itself, is very large - for the larger estimate, it represents substantially more than half of infant mortality in Colombia in 1980. However, both the Brazilian frost and the Brazilian drought resulted in price increases of about 1,250 pesos. Taking the parameter estimates in table 2 in their paper at face value, and focusing on the Brazilian drought, this would mean decreases in infant mortality of between 40 per thousand and 70 per thousand for the median county in Colombia.

26. Even with regard to infant mortality, there is no conclusive agreement. World Bank (2000) concludes that "infant mortality rates seemed to have continued a downward trend (during the crisis)" (cited in Simms and Rowson, p. 1385).

27. The analogy between the effects of weather shocks and macroeconomic contractions on child health and nutrition is not perfect. Weather shocks may be particularly damaging for nutrition outcomes if, in addition to their income effect (and in a context of poorly integrated markets), they directly affect food availability or increase the relative price of food. Furthermore, weather shocks may change the disease environment-for example, a drought may reduce breeding grounds for mosquitoes carrying vector-borne diseases, such as malaria. These effects of the weather shock can themselves have consequences for child health, separate from the income effect.

28. General information about this survey can be found at http://www.caps.uct.ac.za.

29. General information about this survey can be found at http://www.rand.org/labor/FLS/IFLS.

30. One limitation of the analysis by Maccini and Yang is that they do not separate results for positive and negative rainfall shocks. It is possible that gender interacts in important ways with the direction of the rainfall shock — see the discussion of Baird, Friedman, and Schady (2007) above.

\section{References}

Alderman, Harold, John Hoddinott, and Bill Kinsey. 2006. "Long-Term Consequences of Early Childhood Malnutrition." Oxford Economic Papers 58(3):450-74.

Alderman, Harold, Hans Hoogeven, and Mariacristina Rossi. 2009. (Forthcoming). "Preschool Nutrition and Subsequent School Attainment: Longitudinal Evidence from Tanzania." Economic Development and Cultural Change 57(2):239-60. 
Baird, Sarah, Jed Friedman, and Norbert Schady. 2007. "Aggregate Income Shocks and Infant Mortality in the Developing World.” World Bank Policy Research Working Paper 4346.

Baland, Jean-Marie, and James A. Robinson. 2000. "Is Child Labor Inefficient?” Journal of Political Economy 108(4):663-79.

Becker, G.S. 1965. "A Theory of the Allocation of Time." Economic Journal 75(299):493-517. 1991. A Treatise on the Family. Cambridge, MA: Harvard University Press.

Ben-Porath, Yoram. 1967. "The Production of Human Capital and the Life Cycle of Earnings." Journal of Political Economy 75(4):352-65.

Betts, Julian R., and Laurel McFarland. 1995. "Safe Port in a Storm: The Impact of Labor Market Conditions on Community College Enrollments." Journal of Human Resources 30(4):741-65.

Bhalotra, Sonia. (Forthcoming). "Fatal Fluctuations? Cyclicality in Infant Mortality in India." Journal of Development Economics.

Binder, Melissa. 1999. "Schooling Indicators during Mexico's 'Lost Decade'." Economics of Education Review 18(2):183-99.

Black, Sandra E., and Kenneth L. Sokoloff. 2006. "Long-Term Trends in Schooling: The Rise and Decline (?) of Public Education in the United States." In Eric Hanushek, and Fins Welch, eds., Handbook of the Economics of Education. Vol. 1. Amsterdam: Elsevier.

Case, Anne, and Christina Paxson. 2008. "Stature and Status: Height, Ability, and Labor Market Outcomes." Journal of Political Economy 116(3):499-532.

Charles, Kerwin Kofi, and Philip DeCicca. 2008. "Local Labor Market Fluctuations and Health: Is there a Connection and for Whom?" Journal of Health Economics 27(6):1532-50.

Chay, Kenneth Y., and Michael Greenstone. 2003. "The Impact of Air Pollution on Infant Mortality: Evidence from Geographic Variation in Pollution Shocks Induced by a Recession.” Quarterly Journal of Economics 118(3):1121-67.

Currie, Janet, and Duncan Thomas. 1999. "Early Test Scores, Socioeconomic Status and Future Outcomes." NBER Working Paper 6943. Cambridge, MA.

Cutler, David M., Felicia Knaul, Rafael Lozano, Oscar Méndez, and Beatriz Zurita. 2002. "Financial Crisis Health Outcomes, and Ageing: Mexico in the 1980s and 1990s." Journal of Public Economics 84(1):279-303.

Dehejia, Rajeev H., and Adriana Lleras-Muney. 2004. “Booms, Busts, and Babies' Health.” Quarterly Journal of Economics 119(3):1091-130.

Dinkelman, Taryn. 2008. "The Long-Term Effects of Being Born in a Drought: Evidence from the Cape Area Panel Study 2002-06." Paper presented at the 2008 Northeastern Universities Development Consortium Conference, Boston University, Boston, MA.

Duryea, Suzanne, and Mary Arends-Kuenning. 2003. "School Attendance, Child Labor and Local Labor Market Fluctuations in Urban Brazil." World Development 31(7):1165-78.

Duryea, Suzanne, Lam David, and Deborah Levison. 2007. "Effects of Economic Shocks on Children's Employment and Schooling in Brazil." Journal of Development Economics 84(1): $188-214$.

Ferreira, Francisco H.G. and Norbert Schady. 2008. "Aggregate Economic Shocks, Child Schooling and Child Health". World Bank Policy Research Working Paper 4701.

Frankenberg, Elizabeth, Duncan Thomas, and Kathleen Beegle. 1999. "The Real Costs of Indonesia's Economic Crisis: Preliminary Findings from the Indonesia Family Life Surveys." Labor and Population Working paper Series 99-04. RAND Corporation.

Funkhouser, Edward. 1999. "Cyclical Economic Conditions and School Attendance in Costa Rica." Economics of Education Review 18(1):31-50. 
Glewwe, Paul, and Gillette Hall. 1994. "Poverty, Inequality, and Living Standards during Unorthodox Adjustment: The Case of Peru, 1985-90.” Economic Development and Cultural Change 42(4):689-717.

Goldin, Claudia. 1999. "Egalitarianism and the Returns to Education during the Great Transformation of American Education." Journal of Political Economy 107(6):S65-94.

Hoddinott, John, and Bill Kinsey. 2001. "Child Growth in the Time of Drought." Oxford Bulletin of Economics and Statistics 63(4):409-36.

Hoddinott, John, John A. Maluccio, Jere Behrman, Rafael Flores, and Reynaldo Martorell. 2008. "The Impact of Nutrition During Early Childhood on Income, Hours Worked, and Wages of Guatemalan Adults." Lancet 371:411-16.

De Janvry, Alain, Frederico Finan, Elisabeth Sadoulet, and Renos Vakis. 2006. "Can Conditional Cash Transfer Programs Serve as Safety Nets in Keeping Children at School and from Working When Exposed to Shocks?" Journal of Development Economics 79(2):349-73.

Jensen, Robert. 2000. "Agricultural Volatility and Investments in Children." American Economic Review, Papers and Proceedings 90(2):399-404.

Kane, Thomas J. 1994. "College Entry by Blacks since 1970: The Role of College Costs, Family Background, and the Returns to Education." Journal of Political Economy 102(5):878-911.

Kruger, Diana I. 2007. "Coffee Production Effects on Child Labor and Schooling in Rural Brazil." Journal of Development Economics 82(2):448-63.

Lieberman, S., M. Juwono, and P. Marzoeki. 2001. "Government Health Expenditures in Indonesia through December 2000: An Update.” World Bank East Asia and the Pacific Region Watching Brief, Issue 6.

López Bóo, Florencia., 2008. "How do Crises Affect Schooling Decisions? Evidence from Changing Labour Market Opportunities and a Policy Experiment." Paper presented at the 2008 Northeastern Universities Development Consortium Conference, Boston University, Boston, MA.

Lustig Nora, (ed.) 1995. Coping with Austerity: Poverty and Inequality in Latin America. Washington, DC: Brookings Institution Press.

Maccini, Sharon, and Dean Yang. (Forthcoming). "Under the Weather: Health, Schooling, and Economic Consequences of Early-Life Rainfall." American Economic Review.

Maluccio, John A. 2005. "Coping with the 'Coffee Crisis' in Central America: The Role of the Nicaraguan Red de Protección Social." Discussion Paper 188, Food Consumption and Nutrition Division, International Food Policy Research Institute, Washington, DC.

Maluccio, John A., John Hoddinott, Jere R Behrman, Agnes Quisumbing, Reynaldo Martorell, and Aryeh D. Stein. 2008. The Impact of Nutrition During Early Childhood on Education among Guatemalan Adults. Philadelphia, Washington, Atlanta: University of Pennsylvania, IFPRI, Emory.

Martorell, Reynaldo. 1999. "The Nature of Child Malnutrition and its Long-Term Implications." Food and Nutrition Bulletin 20(3):288-92.

McKenzie, David J. 2003. "How do Households Cope with Aggregate Shocks? Evidence from the Mexican Peso Crisis." World Development 31(7):1179-99.

2006. "The Consumer Response to the Mexican Peso Crisis". Economic Development and Cultural Change 55(1):139-72.

Miller, Grant, and Piedad Urdinola. 2007. "Time vs Money in Child Health Production: The Case of Coffee Price Fluctuations and Child Survival in Colombia." Unpublished manuscript, Stanford University.

Del Ninno, Carlo, and L. Mattias Lundberg. 2005. "Treading Water: The Long-Term Impact of the 1998 Flood on Nutrition in Bangladesh." Economics and Human Biology 3(1):67-96. 
Paxson, C.hristina, and S. Norbert. 2005. "Child Health and Economic Crisis in Peru." World Bank Economic Review 19(2):203-23.

Poertner, Claus C. 2008. "Gone with the Wind? Hurricane Risk, Fertility, and Education." Unpublished manuscript, University of Washington.

Pongou, Roland, Joshua A. Salomon, and Majid Ezzati. 2006. "Health Impacts of Macroeconomic Crises and Policies: Determinants of Variation in Childhood Malnutrition Trends in Cameroon." International Journal of Epidemiology 35:648-56.

Ruhm, Christopher. 2000. "Are Recessions Good for your Health?” Quarterly Journal of Economics 115(2):617-50.

Ruhm, Christopher.. 2003. "Good Times Make you Sick." Journal of Health Economics 22(4): $637-58$.

_. 2005. "Healthy Living in Hard Times." Journal of Health Economics 24(2):341-63.

. 2007. "A Healthy Economy Can Break Your Heart.” Demography 44(4):829-48.

Ruhm, Christopher, and William E. Black. 2002. "Does Drinking Really Decrease in Bad Times?" Journal of Health Economics 21(4):659-78.

Rukumnuaykit, Pungpond. 2003. "Crises and Chile Health Outcomes: The Impacts of Economic and Drought/Smoke Crises on Infant Mortality in Indonesia." Unpublished manuscript, Michigan State University.

Saavedra, Jaime. 1998. "Crisis Real o de Expectativas? El Empleo en el Perú antes y después de las Reformas Estructurales.” GRADE Working Paper 25, Grupo de Análisis para el Desarrollo, Lima.

Saavedra, Jaime, and Eduardo Maruyama. 1998. "Los Retornos a la Educación y a la Experiencia en el Perú: 1985-97.” In Richard Webb, and Moisés Ventocilla eds., Pobreza y Economía Social: Análisis de una Encuesta ENNIV 1997. Lima: Instituto Cuánto.

Schady, Norbert. 2004. "Do Macroeconomic Crises Always Slow Human Capital Accumulation?" World Bank Economic Review 18(2):131-54.

Shrimpton, Roger, Cesar G. Victora, Mercedes de Onis, Rosangela Costa Lima, Monika Bloessner, and Graeme Clugston. 2001. "Worldwide Timing of Growth Faltering: Implications for Nutritional Interventions." Pediatrics 107(5):E75.

Simms, Chris, and Mike Rowson. 2003. "Reassessment of Health Effects of the Indonesian Economic Crisis: Donors versus the Data." The Lancet 361:1382-85.

Stillman, Steven, and Duncan Thomas. 2004. "The Effect of Economic Crises on Nutritional Status: Evidence from Russia.” IZA Discussion Paper 1092.

Strauss, John, Kathleen Beegle, Agus Dwijanto, Yulia Herawati, Daan Pattinasarany, Elan Satriawan, Bondan Sikoki, Sukamdi, and Firman Witoelar. 2004. Indonesian Living Standards Before and After the Financial Crisis. Santa Monica, CA: RAND Corporation.

Thomas, Duncan, Kathleen Beegle, Elizabeth Frankenberg, Bondan Sikoki, John Strauss, and Graciela Teruel. 2004. "Education in a Crisis." Journal of Development Economics 74(1): $53-85$.

Walker, Susan P., Susan M. Chang, Christine A. Powell, and Sally M. Grantham-McGregor. 2005. "Effects of Early Childhood Psychosocial Stimulation and Nutritional Supplementation on Cognition and Education in Growth-Stunted Jamaican Children: Prospective Cohort Study." The Lancet 366:1804-07.

Walker, Susan P., Susan M. Chang, Christine A. Powell, Emily Simonoff, and Sally M. GranthamMcGregor. 2007. "Early Childhood Stunting is Associated with Poor Psychological Functioning in Late Adolescence and Effects are Reduced by Psychosocial Stimulation." Journal of Nutrition 137:2464-69. 
World Bank. 2000. "Indonesia: Health Strategy in a Post-Crisis, Decentralizing Indonesia." Sector Report 21318, Jakarta.

. 2001. World Development Report 2000/2001: Attacking Poverty. New York: Oxford University Press.

2007. Malawi Poverty and Vulnerability Assessment: Investing in Our Future. Washington, DC: The World Bank.

2008. Development Data Platform. http://intranet.worldbank.org/WBSITE/INTRANET/ UNITS/DEC/DATA/0,,contentMDK:20200597 menuPK:440073 pagePK:85006 piPK: 85115 theSitePK:84804,00.html.

Yamano, T., Harold Alderman, and Luc Christiaensen. 2005. "Child Growth, Shocks, and Food Aid in Rural Ethiopia." American Journal of Agricultural Economics 87(2):273-88. 